\title{
Authentic documents in the teaching and learning of a foreign language
}

\author{
Caroline C. A. Oyugi
}

\begin{abstract}
Introduction
Today's fast-paced and globalised world has made the learning of a foreign language a pressing need. As a result, many people, already seemingly settled in their occupations are flocking back to college to either learn the basics or master at least one foreign language. However, these attempts do not seem to yield much fruit in terms of applying these 'learned' languages. Many students who have completed foreign language courses are barely capable of sustaining a conversation beyond the standard basic greetings. Learning a foreign language means being able to communicate effectively in everyday situations.
\end{abstract}

Learners of languages tend to be passive in class. They are content with waiting to summarise a whole session's content into a precise mathematical rule. Passivity in class, and the expectation that only the instructor is able to ask questions and consequently supply exact answers to the same questions can be remedied through the use of authentic documents in the course of language teaching and learning.

The language class presents to both the instructor and the learners an opportunity to learn and use a language in its various facets. Here, the learners expect to be taught how to use a language appropriately in different situations of communication. However, a language need not be viewed purely as a regimen of linguistic rules that need be learnt by rote. Language learning eventually entails acquisition of cultural and social norms, comprehension and, to some extent, knowledge of indigenous practices.

Rationale for the use of Authentic Documents

Authentic documents encourage creativity in communication. Learners are inspired to verbalise their thoughts and to think about various scenarios that could present themselves through a single authentic document and the various responses that these scenarios could elicit. This eventually gives rise to the need for the learners to boost their bank of expressions, a bank that will enable them become relevant to the situation. English is the official language of government business and scholarly instruction in Kenya. This does not, however, mean that Kenyan college and university students possess a homogeneous competence in it even as they embark on the study of a foreign language. Variations do exist. However, once in the context of a university, or equivalent setting, there is a minimum acceptable level of competence in English that learners possess that enable the foreign language instructor proceed to exploit authentic documents, particularly those originally presented in the English language, with confidence. 


\section{Adult Learning Strategies}

Mature students who walk into a foreign language class are not quite a tabula rasa as may have been presumed decades earlier. They come to class with accumulated knowledge and experience they have acquired as a result of personal and others' learning experiences [Alan:2004] . This fact alone causes and encourages them to think analogically. They call upon existing knowledge and experience as well the bank of accumulated experience to help them understand the current learning process.

Adult learners are also highly selective of material felt to be relevant to the tasks they need to perform. They will, therefore, try out a number of solutions before eventually settling for an acceptable one. They also rely less on memory and rote-learning mainly due to age and experience, among other factors. Imitation and demonstration, therefore, play a bigger role in helping them learn and retain what is learnt. This observation phase tends to result in having a group of passive recipients of language rather than active participants in the learning process. Adults also tend to look at matters in wholes and then go back to work on the bits that will eventually fit in together. They have little room for ambiguity. It is important to create a pattern that revolves around the key issue.

Language learning calls for sequential and cumulative build up of the diverse nontechnical elements of the foreign language that eventually interconnect to enable them perform a task. Unlike the atmosphere that permeates other classes where the instructor dominates, adult learners are also more self-conscious of their abilities, or lack of them, in a foreign language learning setting. Unlike the case in technical classes, for instance, it is unlikely that the learners will possess more knowledge than the foreign language instructor, at least as far as the various aspects of the language are concerned.

It is also important to note that the learners' motivation for sitting in a foreign language class is not homogeneous. Some may be intrinsically motivated to learn a foreign language just for the sake of it. They do not need yet but believe the language may come in handy sometime in the future. Another group of learners in the same class already need the language for professional advancement and reward; so their push to learn the specific foreign language is extrinsic. Probably given a choice, they would never step into a foreign language class. Another category of learners may be heading to self-actualisation and simply need this particular foreign language to cap their learning or life experiences. Language learning, in this latter case, is simply on the 'to $\mathrm{do}^{\prime}$ list of the learner's agenda in life.

What is an authentic document?

An authentic document is an audio or written document which was not expressly designed for use in a classroom setting or for the study of language, but which responds to an actual function of communication, information or linguistic expression (Coste \& Galisson: 1987). In its raw form, therefore, an authentic document may be defined as a type of verbal of symbolic document originally created with a specific public in mind and which voluntarily fits into its cultural, linguistic and extra-linguistic milieu. It therefore acquires a new identity when introduced into a language class. This is in direct contrast to a document specifically produced or fabricated for pedagogical use, 
or for purposes of formal, pre-designed instruction. The authentic document will, therefore, always be artificial in the sense that it has been uprooted from its real, original and truly relevant situational context.

\section{Why use an authentic document?}

In most cases, foreign language learners will be able to identify the authentic document for what it is. The document may be an advert, a map, a bus/train/ airplane/ cinema ticket, receipt for purchases made in a supermarket, a time-table, the symbol of a political party/ humanitarian organisation/ or movement, a newspaper headline, the programme of events of a cultural center, a song, a promotional flyer for an upcoming event, the day's menu in a hotel, a photograph... the list is inexhaustive.

Learners will also usually be able to identify and name places or situations in which one is likely to meet the specific document. Such documentary and situational identification may very well form part of the learning session. This familiarisation with the authentic document should ideally be done in the target language. How far the instructor stretches the utility of the document will usually depend on the linguistic competence level of the given learning group.

The authentic document is an open-ended opportunity for learners to work on their language: enrich their vocabulary and polish their expressions. This is because the authentic document gives room for linguistic exploration and the exploitation of a wide range of expressions. Language teaching and learning need not be fossilised by routine. Traditional grammar, as instructors of language generally understand, and present it, is usually resented by learners who look at it as a necessary evil they are obliged to sit through so as to fulfil prescribed course requirements. It is no wonder that the language instructor has to look for unusual means of making the learning more palatable.

The foreign language instructor has to be innovative in order to access all the learners' spheres of learning, namely: knowledge, understanding, skills, attitudes and behaviour. Faced with a document he perceives to be out of the usual grammatical context, the learner has the impression that he is about to embark on some exercise that is more appealing and interesting. This change of attitude is all the instructor requires in order to have a more responsive and communicative class.

In line with the principles of the Communicative Approach in language learning, proper use of the authentic document enables the instructor help learners achieve a number of goals which are not limited to but include the following:

i. the encouragement of interactive participation amongst learners during learning sessions;

ii. participation in the joint discovery and discussion of cultural and socio-cultural traits and peculiarities;

iii. the production of authentic communication: here learners are able to communicate as they would in the actual context beyond the boundaries of the classroom environment; 
iv. ability to gauge the extent to with which one is able to express himself and make his ideas understood;

v. identification of key linguistic, semantic and cultural elements of a document;

vi. the construction of sense out of a 'silent' document after initial observation;

vii. the construction of hypothesis around a document

These goals fit well with the linguistic, functional and cultural objectives of the authentic document. Linguistic objectives are expressed in simple terms such as introducing a person or presenting an object to the rest of the class, interrogating a person, describing an object or a place. It calls for a broad us of adjectives. Functional objectives call on the learners' know-how which is to be applied in both the discovery of the document and in its eventual exploitation. Finally, cultural objectives define the thematic fields that the learners may venture into with the help of the documents provided or activities linked to their exploitation.

Which authentic document to use?

In a functional approach, one needs to keep in mind that the learner carries intellectual baggage from which his knowledge is requisitioned from the beginning. The width and depth of this baggage depends on the level of exposure to the target language in active use, the presence or lack of alternatives to using the target language and also on the learner's motivation to acquire competence in the language. In a typical classroom setting, the instructor has a pretty good idea of the average aptitude of the group as a whole as well as of each group member. The authentic document chosen needs to meet the linguistic needs and also correspond to the general interests of the overall group first.

Each authentic document needs to elicit direct and sustained participation of the learners despite disparities in learner ability. In this respect, it calls upon the instructor to thoroughly analyse the target authentic document before brandishing it before confounded language learners. The key question the instructor must have a clear answer to is: "What is the ultimate objective of using the chosen authentic document in the learning session?" The core of the expected response is inevitably to communicate'. However, what specifically does the instructor want to see or hear communicated within the group? Getting a clear answer to this question is crucial since lack of comprehension of a document can also be quite ably communicated. Each document is a boost to communication only to the extent to which it bears some decipherable meaning to the learner.

A language learning session that runs from an hour and half to three hours in one sitting calls for creativity from the instructor and endurance from both parties. Many instructors simply throw in the towel and resort to teaching half- way through the session and giving a written exercise for the remaining part of the session. This is fine, but variety adds colour to life and to learning. Monotony kills interest and learners' attention span, even in the liveliest of sessions, declines with time.

It is not easy to classify or rank authentic documents in terms of levels of complexity. These documents are not focussed for use in language instruction sessions. It is the 
instructor who looks at one and thereafter considers the possibilities of its usage in a language class. Recurring themes do not necessarily constitute a problem but are useful in reinforcing certain aspects of language. After all, in language learning and use, repetition enables reinforcement.

It is easier, then, to attempt a classification in terms of themes presented as well as the range of language exercises possible from each one of them. With continued use and practice, eventually an instructor learns to discriminate between the wide range of options readily available in the learners' environment. With time and experience, he may even begin combining some so that the learners can simultaneously take into account aspects gleaned from both.

\section{Phases in using an Authentic Document}

The initial step in using an authentic document is a phase of observation and of discussion. This calls for the instructor to withdraw from being the center of focus and the source of knowledge for some moments. The 'off-instructor' time is left to the intuition and creativity of the learners. The learners, now in charge of their learning for some time, are then free to pick out what interests them. The learners begin to own the learning process. The more they are able to relate to the material presented before them, the more productive the learning session is likely to be.

In its initial stages, the authentic document sets out to encourage efficient and relevant use of language rather than highlight linguistic error detection and correction. It can be frustrating to work with a language learner who has perfectly understood and memorised a linguistic structure, but who is utterly incapable of producing the same structure in the course of a spontaneous conversation. Language is intended to facilitate spontaneous communication. Levels of correctness will vary with learner aptitude as well as with the situation presented by each authentic document.

Despite the variations, the ultimate objective is to stimulate the learners to engage in some comprehensible form of verbal intercourse. In due course, the learner is able to progress from the basic identification of objects, places and words to responding to questions directly referring him to the authentic document and finally to creating a dialogue or story based on, or inspired by the document that has been furnished. The learner therefore progresses from the stage of assimilation where $\mathrm{s} / \mathrm{he}$ imitates what the instructor, or other learners do, to accommodation, where s/he is truly her/himself. In this sense, the authentic document serves well to advance the cause of communication. It helps drive the point home that language is not merely useful for transmitting information, but also for one to react to his world and to others.

Irrespective of the theme or nature of the authentic document chosen, the learners need to be allowed time to familiarise themselves with it. Ideally, sufficient copies of the document, in the same version and dimension, need to be availed, especially in the case of visual documents. Audio and audio-visual authentic documents need to be strategically positioned and clear enough for all. 
Once learners have placed the given document in a specific context, they then move to the next phase. This is the phase of anticipation and reconstitution. Here, the learners, preferably in small groups or pairs, decide what to do with the document at hand. What should be clear is that they need to create a situation demanding interaction, with the document as their inspiration. The communicative approach to language teaching and learning is centered on dialogue. Invariably, dialogues, with the interlocutors playing clear roles, tend to emerge.

Even in the most predictable of situations, when learners are allowed the freedom to simply think for themselves, they come up with the most ingenious settings for their conversations. Motivation appears to be based on the pre-judged value of the task at hand. The more the learners believe they can perform the task well, the more they put into ensuring a proper execution. This includes taking linguistic risks and venturing to employ new, unfamiliar and recently discovered words and expressions. It is important for learners to develop confidence about their ability to satisfactorily perform communicative tasks.

A communicative task involves learners in comprehending, manipulating, producing or interacting in the target language (Numan:1989). The principal focus is on meaning rather than what incites the linguistic production. This calls for the gradual development of skills, behaviour and etiquette that spur foreign language learners to excel. The obstacles presented to them need to be viewed as surmountable by even the most timid learner in the group.

Group work and activities in themselves may pose unexpected problems to the inexperienced instructor. This comes in the form of learners' personality. Learners are introverted or extroverted, competitive or cooperative, independent or dependent and finally, cautious or impulsive. The best results from group exercises tend to be the result of consensus, cooperation and mutual agreement. Certain speech acts are likely to be particularly pertinent as they immediately correspond to the learners' preferred or familiar range of activities such as expressing one's interests, proposing possibilities, talking about facts, expressing and defending one's opinion, asking for and offering help.

Communicative tasks should ideally involve learners' reasoning. This involves making connections between pieces of information, deducing new information as well as evaluating information. Cognitive processes such as selection, classification, sequencing and transforming information from one representation to another all take place in the analysis of an authentic document. Learners, consequently, will almost always need to address the following immediate concerns:
i. Where am I?
ii. What is happening/ has taken place?
iii. To whom will I address myself?
iv. What will/ can I say?
v. How will/ can I say it?
vi. What is being asked of me? 
vii. How can/ should I respond? Is my response appropriate?

Ideally, the group then agrees on how to go about the presentation of their conversation. Without getting too technical, learners are usually able to create authentic situations of interaction in which they are free to express themselves.

Preparation is consequently followed by presentation. The learners' and instructor's main role here is to observe and appreciate the various interpretations given to the authentic document initially provided. In general, all authentic documents are expected to ignite and prioritise oral or verbal expression without ignoring the linguistic aspect of language learning. Frequency in relevant use of authentic documents helps learners and the instructor to regularly practise activities that come in handy in other situations of learning. In this respect, authenticity concerns whether a task and the eventual production correspond to some real world activity to which the learner has responded in a non-conditioned manner.

\section{Concerns over the use of Authentic Documents}

Authentic documents in themselves do not present obstacles in the teaching and learning of a foreign language. This is based on the fact that none of them was originally fashioned to facilitate linguistic advancement, but to play communicative roles in their respective domains. Drawbacks in their use and the reduction in their effectiveness are, thus, attributable to factors relating to either the foreign language instructor or the learner. These include the instructor demanding a lot of information from the learners, especially at the onset of authentic document exploitation. This can discourage learners who are not yet accustomed to consolidating their learning experiences and knowledge to produce a text of reasonable linguistic value.

Introductory authentic documents can be used to simply elicit one-word responses, short answers and encourage basic expression of personal interests and preferences. The same specimens can be revisited at a later date for more detailed or advanced exercises. In fact, the same document can be successfully used learners in beginner, intermediate and advanced classes, the variation being the type of work expected of them and the extent of instructor involvement in the sessions.

Overuse of authentic documents can also cause some learners to lose track of the learning process. Learners need time to reflect and appreciate how each authenticdocument- punctuated session fits in with what has been learnt. Authentic documents are a complement to, and not a replacement of the instructor's role. From the above, one can also deduce that they work best in a situation where the learners have actually been taught some aspects of grammar, culture and civilisation of the target language.

Cultural sensitivity is also required on the part of the instructor, when choosing an authentic document. For example, having learnt about various members of the family, it is unlikely that a class will respond enthusiastically to a clipping from the obituaries from which they are expected to either construct a genealogical tree or talk about members of their families. Allow such information to come from the learners rather than impose it on them. Learners respond best when they express themselves on issues out of choice, rather than out of obligation. 
As often as possible, the instructor is encouraged to vary the stimuli. People learn differently. Some benefit most from aural stimulation, others from visual stimuli while others are verbal based. A number of language learners will present a combination of preferred stimuli. It helps if the instructor responds to these needs especially in multicultural classroom settings.

Authentic documents often bear messages that are culturally conditioned or culturesensitive. This is unavoidable as all languages carry an aspect of culture with them. What would pose as a problem is if the document is seemingly offensive to a section of the learners in the class. Screening of documents for aspects that are obviously offensive is in order. It is actually of no negative consequence, in my view, if learners spend time going over other aspects of the authentic document that they do not intend to include in their final presentation. As long as these aspects do not present too much of a distraction, the instructor should allow for a thorough exploration and exploitation of the given document.

\section{Conclusion}

The authentic document is one teaching tool that every foreign language instructor is encouraged to adopt into the teaching and learning sessions. It is readily available, sometimes more available than the prescribed or the ideal class texts. It liberates the instructor from having to be the only foreign language speaker within the group. It also challenges learners to rise to the challenge of being active participants in the foreign language learning process.

Using authentic documents present foreign language learners with opportunities to enrich their vocabulary. As they seek to express themselves in the target language with ease, they also become more adept at organising linguistic material they have learnt into meaningful sequences. Learners also gradually learn to observe their environments more keenly as they realize that they can learn and be inspired from the most unlikely of sources. Employing a variety of authentic documents that they may end up supplying from their own sources, they encourage each other to spontaneously engage in conversations and discussions that are out of the box that the four walls of the classroom represent.

Using authentic documents in the teaching-learning process gives learners the opportunity to look for information beyond what the instructor provides on the board. It encourages learners to actively use, rather than merely display language. It is at such a point that they can be credited with learning a language since language is meant to be employed to bridge social distance. When the learners graduate from the foreign language class, then, are they truly knowledgeable. After all, knowledge is experience; everything else is just information. 


\section{References}

1. Alan R. (2004), Teaching Adults; (2004), Open University Press.

2. Galisson R. \& Coste D. (1987), Dictionnaire de Didactique Des Langues: Hachette.

3. Numan, D. (1989), Designing Tasks for the Communicative Classroom; Cambridge 